\title{
ALÉM DE UM PROGRAMA CURRICULAR: A FORMAÇÃO ESTÉTICA DE PROFESSORAS/EDUCADORAS DAS INFÂNCIAS ${ }^{1}$
}

\author{
Beyond a curricular program: the aesthetic education of pre-school and primary school \\ teachers
}

\begin{abstract}
Además de un programa curricular: la formación estética de profesoras / educadoras de las infâncias.
\end{abstract}

\author{
Luciana Esmeralda Ostetto* \\ Maria Assunção Folque* \\ Isabel Bezelga*
}

\begin{abstract}
Resumo
As dimensões interculturais implicadas na profissão docente requerem que não se descuide das dimensões estéticas nos cursos de formação de professores e educadores, reconhecendo a necessidade de aprendizagem no campo das linguagens expressivas, tanto no âmbito pessoal quanto no profissional. Perpassando tais questões, o artigo discute dados da investigação que teve entre seus objetivos analisar a presença das dimensões estética e cultural nos currículos de formação docente para a educação infantil e nos percursos de professores em formação inicial da Universidade de Évora (PT). $\mathrm{O}$ traçado teórico-metodológico contou com a realização de encontros-ateliês com os estudantesprofessores, como espaço-tempo de tecer memórias e narrativas sobre percursos de formação estética. $\mathrm{O}$ exercício de rememorar situações que marcaram a educação de sua sensibilidade, mediado pelo contato com múltiplas linguagens ao longo dos encontros-ateliês, projetou narrativas que permitiramnos identificar elementos-chave dos processos de educação estética ao longo da vida e, com eles, refletir que os cursos de formação docente devem garantir espaço-tempo para experimentação, expressão, criação. Para além de aulas de arte isoladas, a importância de cultivar articuladamente sensibilidade e pensamento, memória e novas experiências, no contato com a natureza, a cultura, a arte, foi referendada.
\end{abstract}

PALAVRAS-CHAVE: Formação Estética. Arte. Narrativas Docentes.

\section{Abstract}

The intercultural dimensions involved in the teaching profession require that one do not neglect the aesthetic dimensions in the teachers' training courses, recognizing the need for learning in the field of

\footnotetext{
${ }^{1}$ A investigação que dá base ao presente artigo foi desenvolvida junto à Universidade de Évora - Portugal e recebeu apoio do Programa Professor Visitante no exterior 2017/2018- CAPES n ${ }^{\circ}$ 45/2017.

${ }^{*}$ Doutorado em Educação. Universidade Federal Fluminense (Brasil). Líder do FIAR - Círculo de estudo e pesquisa Formação de professores, Infância e Arte. Professora do Curso de Pedagogia e do Programa de Pósgraduação em Educação (mestrado e doutorado). E-mail: lucianaostetto@id.uff.br

${ }^{*} \mathrm{PhD}$ Education. Universidade de Évora (Portugal). Pesquisadora do CIEP - Centro de Investigação em Educação e Psicologia. Professora Auxiliar do Departamento de Pedagogia e Educação. Docente do Mestrado em Educação Pré-escolar. Diretora do Mestrado em Educação Pré-escolar e Ensino do 1. ${ }^{\circ}$ Ciclo do Ensino Básico. E-mail: mafm@uevora.pt

${ }^{*}$ PhD Teatro. Universidade de Évora (Portugal). Professora Auxiliar do Departamento de Pedagogia e Educação. Docente de Educação Artística e Teatro. E-mail: imgb@uevora.pt
} 
expressive languages, both personally and professionally. The article discusses data from a research aimed to analyse the presence of the aesthetic and cultural dimensions in the curricula of early childhood teacher education and in the student/teachers' trajectories in initial training at the University of Évora. The theoretical-methodological framework of the study rests in the interface between education, culture and art. The realization of workshops-meetings with students-teachers configured as a space-time to weave memories and narratives about aesthetic developmental trajectories. The exercise of recalling situations key to their own education of sensibility, mediated by the contact with multiple languages throughout the workshop-meetings, projected narratives that allowed us to identify key elements of the processes of aesthetic education throughout life and, with them, to reflect that teacher training courses should guarantee space-time for experimentation, expression, creation. In addition to isolated art classes, the importance of cultivating sensitivity and thought articulately, memory and new experiences in contact with nature, culture and art, was endorsed.

KEYWORDS: Aesthetic Education. Art. Teachers' Narratives.

\section{Resumen}

Las dimensiones interculturales implicadas en la profesión docente, requiere que no se descuida de las dimensiones estéticas en los cursos de formación de profesores y educadores, reconociendo la necesidad de aprendizajes en el campo de los lenguajes expresivos, tanto en el ámbito personal y en el profesional. En el artículo se discute datos de la investigación que tuvo entre sus objetivos analizar la presencia de las dimensiones estética y cultural en los currículos de formación docente para la educación infantil y en los itinerarios de profesores en formación inicial de la Universidad de Évora (PT). En el trazado teórico-metodológico la realización de encuentros-talleres con los estudiantesprofesores se presentó como espacio-tiempo de tejer memorias y narrativas sobre recorridos de formación estética. A lo largo de los encuentros-talleres, el ejercicio de rememorar situaciones que marcaron la educación de su sensibilidad, proyectó narrativas que nos permitieron identificar elementos clave de los procesos de educación estética a lo largo de la vida y, con ellos, reflexionar que los cursos de formación docente deben garantizar espacio-tiempo para experimentación, expresión, creación. Además de clases de arte aisladas, la importancia de cultivar articuladamente sensibilidad y pensamiento, en el contacto con la naturaleza, la cultura, el arte, fue refrendada.

PALABRAS CLAVE: Formación Estética. Arte. Narrativas Docentes.

\section{INTRODUÇÃO}

\section{À maneira de introdução: pesquisar com professoras e educadoras das infâncias}

Nas últimas décadas, no campo da pesquisa e da prática pedagógica com/na educação infantil, as experiências e os saberes das crianças são afirmados e ganham protagonismo na construção dos currículos. O reconhecimento de "mudanças na ecologia da infância e no seu inter-relacionamento com diversas esferas da sociedade global" (FOLQUE, 2018, p.33), pauta a necessidade de se repensar o papel do professor e/ou educador de infância e, em decorrência, revisar a sua formação. No contexto de uma profissão complexa, social e culturalmente implicada na construção de um futuro sustentável (FOLQUE, 2018), a imagem da criança produtora de cultura, criativa, sujeito de direitos e de múltiplas linguagens, está a exigir um adulto-professor-educador competente e criativo. Pois, como dissera a pedagogista italiana,

[...] não haverá criatividade na criança se não houver criatividade no adulto. Teremos uma criança competente e criativa se houver um adulto competente e criativo. Por essa razão é absolutamente indispensável reconsiderar a nossa relação com a arte como uma dimensão essencial do pensamento humano (RINALDI, 2012 p. 193). 
Incluir nas propostas de formação de professores e/ou educadores questões concernentes à arte, é reconhecer a necessidade de desenvolvimento e aprendizagens no campo das linguagens expressivas tanto no âmbito pessoal quanto na prática docente (LEITE; OSTETTO, 2004; BEZELGA, 2018; OSTETTO; SILVA, 2018). Na contemporaneidade, reconhecida a diversidade cultural que atravessa as realidades sociais e educativas, os conhecimentos que envolvam arte e cultura são inegavelmente necessários à docência: para poder acolher e ensinar crianças provenientes de diferentes formações culturais, exige-se do professor/educador uma condizente formação artístico-cultural. Nesses tempos, consolidar a profissionalização docente levando em conta a complexidade cultural e, por isso mesmo, o acolhimento das dimensões interculturais da profissão (FOLQUE, 2018), requer que não se descuide das dimensões estéticas, que se potencialize os aspectos artístico-culturais na formação. Ademais, como sustenta a tese de Marta Nussbaum (2015), as artes e as humanidades são componentes essenciais para a sustentação de uma sociedade democrática. Segundo a filósofa norte-americana, as humanidades, de modo geral, e a arte, de modo particular, estão no cerne do desenvolvimento de competências "para o bem interno de qualquer democracia e para a criação de uma cultura mundial generosa [...]" (NUSSBAUM, 2015, p. 15). Ao defender sua tese, aponta algumas das competências ligadas às humanidades e às artes: "[...] a capacidade de pensar criticamente; a capacidade de transcender os compromissos locais e abordar as questões mundiais como um "cidadão do mundo"; e, por fim, a capacidade de imaginar, com simpatia, a situação difícil em que o outro se encontra." (NUSSBAUN, 2015, p. 8).

Além de garantir a arte e as diferentes linguagens expressivas no desenho curricular dos cursos de formação docente, não descuidar das dimensões estéticas passa, também, por conhecer percursos e histórias de vida daqueles em formação. Concordamos que "O professor é a pessoa; e uma parte importante da pessoa é o professor" (NIAS, 1991 apud NÒVOA, 2007, p.15) e, de tal forma, reconhecer as singularidades, as maneiras próprias de cada um produzir seus processos formativos, torna-se elemento relevante a ser observado e considerado no percurso.

É nesse horizonte compreensivo dos processos formativos docentes que se inscreveu a pesquisa que dá base ao presente artigo. Desenvolvida na Universidade de Évora, a investigação teve entre seus objetivos analisar a presença das dimensões estética e cultural nos currículos de formação docente para a educação infantil e nos percursos de professores em formação inicial. Contou com a colaboração de estudantes dos cursos de Licenciatura em Educação Básica - LEB, do Mestrado em Educação Pré-escolar e do Mestrado em Educação Pré-escolar e Ensino do $1^{\circ}$. Ciclo do Ensino Básico da Universidade de Évora ${ }^{2}$.

O exercício de perscrutar as miríades de situações cotidianas, dentro e fora da escola, na família, na rua, na comunidade e que, nas vozes das estudantes, projetam-se em significados formativos pelos canais da sensibilidade, guiou o traçado teórico-metodológico deste estudo. Com esse foco seguiu a produção de dados, valendo-se da realização de quatro

\footnotetext{
${ }^{2}$ Em Portugal a habilitação para a docência na Educação Infantil e no Ensino Fundamental configura-se em duas fases: Licenciatura em Educação Básica de 3 anos comum a todos os docentes (educação infantil e ensino fundamental $1^{\mathrm{a}}$ a $6^{\mathrm{a}}$ série), mais um mestrado de 3 ou 4 semestres conforme se opte, respectivamente, por habilitação para educação infantil ou ensino fundamental ( $1^{\mathrm{a}}$ a $4^{\mathrm{a}}$ serie) ou por uma habilitação que combina as duas valências (caso do Mestrado em Educação Pré-escolar e Ensino do $1^{\circ}$ Ciclo do Ensino Básico). Os diversos cursos de formação inicial incluem as seguintes áreas de formação: Área de docência (AD - incluindo Língua Portuguesa, Matemática, Ciências naturais e História e Geografia, Expressões artísticas); Área educacional geral (AEG); Didáticas específicas (DE) ; Área cultural, social e ética (ACSE); Iniciação à prática profissional (IPP) (DL 79/2014 - Art. $^{\circ}$ 7. ${ }^{\circ}$ ). Para mais informação ver: FOLQUE, 2018; FOLQUE, LEAL-DA-COSTA, ARTUR, 2016)
} 
encontros-ateliês com dois distintos grupos de estudantes, com periodicidade quinzenal, entre os meses de outubro e dezembro de 2018. A participação foi livre, com inscrições a partir de convite às turmas dos cursos referidos anteriormente, sendo que os ateliês aconteceram de forma extracurricular, ou seja, para além da carga horária das disciplinas acadêmicas que cursavam no semestre.

As sessões foram documentadas (pequenos vídeos, fotografias, registros em caderno de notas), sendo que entre os dados/materiais de análise está um dispositivo que chamamos de "Caderno de memórias \& miudezas", produzido individualmente pelas alunas-participantes e sobre o qual falaremos adiante.

\section{Formação estética, formação cultural: tecendo entendimentos}

O sujeito ético, aspiração do projeto pedagógico moderno, se constitui numa pluralidade de experiências e numa abertura ao mundo e ao outro para os quais a experiência estética, enquanto um horizonte aberto, assume um sentido eminentemente formativo. (HERMANN, 2005, p. 75).

A posição indicada pela autora na epígrafe, ajuda-nos a pensar a experiência estética como possibilidade de ampliação das relações éticas com o mundo, sobremaneira no campo educacional, nos espaços escolares: na medida em que oferece mais informações e representações múltiplas de experiências e conhecimentos, pode expandir as possibilidades de reconhecimento das diferenças, do respeito aos pontos de vista alheios e, portanto, pode contribuir para o reconhecimento do outro enquanto semelhante e diferente e para a resolução de conflitos entre grupos e comunidades.

Ao colocarmos em questão a dimensão estética na formação docente, colocamos em foco as experiências, os tempos, os espaços, as relações por meio das quais os sujeitos (no caso, os estudantes em processo de formação docente) aprenderam a dar, e dão, sentido às coisas do mundo; buscamos identificar movimentos que ajudaram àqueles em formação universitária a conectarem-se com sua potência criadora, a animarem sua vida, a olharem para si e para o outro, significando a vida em sociedade.

Animar, aqui, vem do diálogo com James Hillman (1993), que ao trazer para a discussão sobre estética os princípios da filosofia fiorentina clássica, afirma que perceber o mundo com os sentidos é arfar, inspirar, conduzir o mundo para dentro. Tais movimentos configurariam o centro da atividade estética, pois impulsionam a percepção, o sentir-animar o mundo. É por meio da reação estética que conhecemos o mundo, é por ela/com ela que animamos o mundo, a medida em que somos afetados - pelos seus cheiros, sabores, cores, formas, sons -, e com ele implicamo-nos, ou seja, deixamo-nos afetar pelo que nos passa, não ficamos indiferentes à multiplicidade que se apresenta ao nosso ser corpóreo-sensível. (HILLMAN, 1995).

O sentido de estética, da raiz grega "aisthesis, indica a primordial capacidade do ser humano de sentir a si próprio e ao mundo num todo integrado" (DUARTE Jr., 2001, p. 13). Sensação, sensibilidade, sensopercepção, conhecimento sensível-sensorial são significados associados à palavra estética. Compreende-se, pois, que a educação estética se relaciona aos processos de percepção, de imaginação, de interpretação que, na interação do homem com o mundo - arte, cultura, natureza -, contribuem para alargar a sensibilidade (PERISSÉ, 2009).

Desde essa compreensão, temos que a formação estética vai além da beleza, do conhecimento e da fruição da arte, podendo "[...] ocorrer também em situações cotidianas, assistindo a um jogo, vendo uma tapeçaria, diante de cenas da natureza, ouvindo música, lendo uma poesia etc. A estética se relaciona com a nossa capacidade de aprender a realidade 
pelos canais da sensibilidade" (HERMANN, 2014, p. 124). Por meio das relações e experiências compartilhadas nos contextos socioculturais em que vivemos e transitamos, vamos nos apropriando de modos de ser, pensar e sentir, elaborando sentidos e significados sobre o mundo e, assim, vamos nos formando esteticamente.

Por esses caminhos, sem dúvida o contato com a arte e com os artefatos culturais contribui para o refinamento e a ampliação dos modos de apropriação e expressão do mundo. De tal maneira é que, no contexto educacional,

O valor da educação artística reside precisamente na sua capacidade de interpelar, através da exploração, criação e fruição de universos simbólicos e sensíveis pessoais, na possibilidade em desorganizar certezas nas abordagens de conceitos e desmontar temas tabus. A competência para colocar questões, no sentido interrogativo da existência, é bem mais difícil que encontrar respostas (BEZELGA, 2018, p.169).

Explorar, criar e fruir arte, como experiência configurada em campos simbólicos e sensíveis, certamente provoca deslocamentos do instituído e, ao fazê-lo, fertiliza possibilidades outras para o ser no mundo, no encontro com o outro, reconhecendo e acolhendo a diferença que nos constitui. Explorar, criar e fruir arte, como oportunidade de interpelar-se diante da vida, tornam-se movimentos essenciais para o profissional que, na escola ou em instituições de Educação Infantil, tem ao seu redor sujeitos-crianças que estão sempre a questionar o mundo, ávidas pela criação, curiosas de toda a novidade, disponíveis para a experimentação e pesquisa, de corpo inteiro. Nessa direção, o profissional da educação infantil, professor e/ou educador de infância, assume o importante papel de mediador cultural.

[O professor é] mediador de culturas: as da infância, as culturas próprias de cada comunidade e aquelas acumuladas pelo desenvolvimento humano nas ciências, nas artes, nas humanidades e nos quotidianos. Este papel de mediador cultural implica que a formação se constitua como um espaço de enriquecimento cultural forte, e que os futuros estudantes se assumam enquanto cidadãos na sua formação e também na sua profissão (futura)". (FOLQUE, 2018, p.44).

Nesse contexto, olhando os sujeitos com os quais um professor/ educador de infância vai conviver e atuar profissionalmente, cuidar da dimensão cultural da formação é imprescindível pois, como destacou Folque (2018, p. 44-45), “[...] quem não sentiu com o corpo todo, quem não experimentou a imaginação, a criatividade e a dimensão estética na sua relação com esse mundo, dificilmente se pode tornar um mediador cultural". A experiência com todos os sentidos, corpo inteiro, é essencial nesse caminho, seja ampliando espaços já vivenciados ao longo da vida, seja abrindo novos espaços na trajetória acadêmica, que promovam e integrem as dimensões estético-artístico-culturais (BEZELGA, 2018).

A formação estética, nessa perspectiva, vai além de um programa escolar, além de propor experimentos de composições plástico-pictóricas, de ouvir uma música ou de fazer teatro durante a formação de professores, por exemplo. Compreendemos, pois, que "[...] a educação estética começa como educação de si mesmo e de suas relações com os outros e o mundo em sua abrangência e infinitude" (GALEFFI, 2007, p. 107), é relação empática com o mundo, é o contrário da indiferença (VECCHI, 2013), é o oposto da anestesia, que desanima o mundo, que lhe retira seu (im)pulso de vida.

\section{Os espaços da pesquisa: encontros-ateliês}

Para pesquisar a dimensão estética implicada na jornada de formação de docentes da Educação Infantil, é imprescindível abrir espaço para a enunciação de narrativas pessoais. $\mathrm{O}$ reencontro daquele em formação (do professor e educador, no nosso caso), com suas 
linguagens, é potencializado quando há espaços que encorajam a escrita de si, apoiado por fazeres artesanais, que contribuem para o mergulho nas suas histórias de vida, para buscar imagens que falam dos processos de constituição das subjetividades (OSTETTO; BERNARDES, 2015; OSTETTO, 2016). Assim, no traçado metodológico recorremos, como referência inspiradora, à proposta do ateliê biográfico, compreendido como

[...] um procedimento que inscreve a história de vida em uma dinâmica prospectiva que liga o passado, o presente e o futuro do sujeito e visa fazer emergir o seu projeto pessoal, considerando a dimensão do relato como construção da experiência do sujeito e da história de vida como espaço de mudança aberto ao projeto de si (DELORY-MOMBERGER, 2006, p.359).

Ao dizer que a proposta de Delory-Momberger (2006) serve-nos de inspiração, é preciso explicitar que os ateliês desenvolvidos seguiram também outros fundamentos teóricopráticos: os princípios do ateliê de arte, igualmente contribuíram para a apropriação e proposição de ações pelas quais o rememorar é potenciado por meio de diferentes linguagens expressivas (pintura, recorte-colagem, desenho, música, dança, entre outros), além da palavra. De outro modo, os fundamentos de uma "pedagogia da autonomia" (FREIRE, 2004), que evidencia a imprescindível relação dialógica na construção do conhecimento, onde a escuta atenta e o acolhimento às diferenças são bases do trabalho formativo-educativo, também sustentaram a dinâmica dos encontros-ateliês então projetados como espaço de produção de dados biográficos e dados para a pesquisa.

Os encontros foram realizados em uma sala de aula que, a cada dia, era preparada para receber as participantes: considerando a potencialidade da forma circular, o espaço era arranjado afastando as mesas para deixar um espaço vazio e no qual pudéssemos nos sentar em roda. As atividades propostas eram, então, desenvolvidas ao redor de um centro composto para cada encontro - sob um pano colorido, ou uma toalha circular, colocamos materiais e/ou objetos que simbolizavam questões que seriam abordadas ou seriam utilizados nas propostas a serem encaminhadas no dia.

Os encontros, conforme a fundamentação que sustentou a proposta, prezou pelo emprego de múltiplas linguagens, configurando experiências que se desenvolviam entre teoria e prática, entre reflexões e contato direto com diferentes materialidades expressivas. A dimensão experimental nas aprendizagens estéticas é um princípio central, quando falamos de processos formativos docentes, a qual é potencializada na reflexão que engendra e amplia a consciência de si, a medida em que se entrega ao fazer.

Experimentar, experimentar, experimentar... E pensar! É importante que as práticas de experimentação decorram em sintonia com processos de tomada de consciência e de autorreflexão [...]. Pensar em ação possibilita acesso a diferentes perspectivas e implicar-se no diálogo entre educação e arte (BRAMFORD, 2006). E esse cruzamento com complementaridade é fundamental. De certa forma, corresponde à procura do(s) sentido(s) que mobilizam os artistas contemporâneos. Um primeiro passo consiste na criação de um espaço de disponibilidade, onde se possa experimentar para nos descobrirmos e descobrir para nos conhecermos. (BEZELGA, 2018, p.176)

Com esse princípio, cada sessão começava geralmente com uma cantiga, chamando para a roda, saudando a todos e abrindo espaço à conexão e à harmonização do grupo para o trabalho coletivo que se seguiria. As cantigas escolhidas tinham uma propriedade especial: podiam também ser dançadas. Com movimentos simples e integradores, foram propostas como um chamado para a presença de corpo inteiro na roda. 
Também recorremos à literatura, realizando rodas de histórias, com a leitura dos livros: "Guilherme Augusto Araújo Fernandes" (FOX, 1995), para evocar questões da memória e "Os cinco sentidos" (QUEIRÓS, 2009), para dialogarmos sobre a apreensão do mundo por todos os nossos canais sensíveis. De modo geral, fez-se um convite à busca por territórios desconhecidos, que pudessem acionar regiões silenciadas dos fazeres sensíveis. Como, por exemplo, na proposta oferecida em um dos encontros, de desenhar com carvão vegetal, em duplas, sobre um suporte de papel Kraft disposto na parede.

Desenhar... invariavelmente, entre educadores, a falta de intimidade com o desenho, ou a intimidação para a autoria gráfico-pictórica, imposta ao longo do percurso escolar, é visível. Também com as participantes da pesquisa essa é uma marca, como podemos perceber em suas narrativas a respeito: "Na escola, o desenho era olhar e copiar"; "Fiquei com a ideia de que não tenho jeito para desenhar. Mas gosto de pintar."; "Não sei se vem da escola ou não, mas acho que não é fácil desenhar. Eu até desenho, se preciso for, mas não me sinto à vontade desenhando"; "Na escola eu desenhava o que era obrigada, fazia sem gosto. Lembro que a professora ajudava a arranjar o desenho que não estava bem"; "Minha irmã desenha muito bem. Mas eu não tenho jeito, não sei fazer. Eu ficava olhando os desenhos dela e gostava". (Notas de campo).

O objetivo não era dar forma, definir antecipadamente um desenho, mas deixar correr o risco com aquela materialidade singular e pouco usual, conforme atestavam as próprias participantes. Chamava a sair do lugar de conforto, conhecido. Provocava a experimentação, a criação, por meio de diálogos do fazer, marcando o suporte com traços do carvão vegetal, esfumando-o ou recobrindo-o com outras texturas. Ensaiava-se a ruptura com as noções escolares e sociais do certo e do errado, do belo e do feio, assinalava-se a necessidade de olhar com disposição para o que não se conhece e se colocar em experiência para poder construir (outros) significados.

Como uma linha que cruza, apoia e articula todos os encontros-ateliês e as linguagens oportunizadas/evidenciadas, propusemos e utilizamos o "Caderno de memórias \& miudezas", abarcando e abraçando atos de memória, reflexão e expressão. Como um dispositivo singular de produção de dados biográficos, o referido dispositivo foi criado na interseção entre duas formas de registro: o caderno de artista e o diário.

No campo da arte, é conhecida a prática de artistas traçarem esboços, desenhos e observações, por vezes colagens, que referenciem ideias e processos cotidianos, rascunhos de pensamentos e hipóteses, utilizando-se de pequenos cadernos ou blocos, constituindo o que se tem chamado de "caderno de artista" ou "livro de artista" (SILVEIRA, 2001). No campo da educação, o "caderno de registro", ou "diário", vem sendo utilizado entre professores e educadores, sobretudo na Educação Infantil, como prática de documentação que fertiliza a reflexão sobre os fazeres docentes na relação com as crianças (WARSCHAUER, 1993; OSTETTO, 2008). No caderno de registro é a linguagem escrita que prepondera, ainda que diferentes estilos ou gêneros textuais possam ser assumidos, a depender do seu autor. Aproximando práticas da educação e da arte, o "Caderno de memórias \& miudezas" foi proposto como suporte para abrigar coleções de ideias, imagens, fragmentos do viver, recolhidos do fundo da memória e considerados importantes para a pessoa-narradora.

Significados que ficam à espreita, nem sempre conscientes, mas cheios de oportunidades para a reflexão, para a amplificação de sentidos e aprendizagens cunhados da memória, podem projetar-se e vir à luz nas páginas do caderno, que contava com uma espécie de roteiro para ativar memórias, prevendo um caminho de conexões com as sensibilidades, com todos os sentidos. Lembrar o quê? Lembrar por onde? Pelos Sabores, Cheiros, Cores, 
Texturas, Um objeto para lembrar, Meus brincares, Afetos, Cantar cantigas, Sítios preferidos, Mapa do meu quintal, Uma saudade, Uma história inesquecível.

Ao longo dos encontros, cada participante, de posse de seu caderninho, foi compondo suas memórias, utilizando-se dos materiais disponibilizados num canto da sala (tesouras, cola, lápis de cor, canetinhas coloridas, recortes de revistas - palavras e imagens, folhas coloridas), em forma de mini-ateliê.

\section{Retratos da arte na escola, traços de formação estética}

Entre os vários conteúdos visibilizados nos Cadernos de memórias \& miudezas e nas narrativas orais ou escritas produzidas no contexto dos encontros, trazemos para o presente artigo aqueles que tematizam as experiências com as expressões artísticas na escola ${ }^{3}$ : desde a creche e o jardim de infância/pré-escola, passando pelos ciclos da Educação Básica e chegando à Universidade.

Da presença da arte na Creche e no Pré-escolar, contam: "Arte no Jardim de Infância... Desenhar, pintar, decorar, cantar, dramatizar... um pouco de tudo, na verdade" (C.); "Trabalhos ligados à estética eram: enfeites para a sala, desenhos, prendas do dia da mãe, do dia do pai, construção dos nossos fatos de carnaval, etc. "(M.); "Quando estava no jardim, eu queria desenhar e colocar na parede o meu desenho. Hoje eu vejo paredes brancas, vazias, nas escolas onde vou" (B.).

Nos encontros, nas narrativas orais, quando se reportavam ao tempo do jardim de infância, falavam sempre com alegria, prazer, recordando-se como uma boa experiência. Quando falavam da escola, faziam referência à imposição de modelos, à obrigação de "pintar no risco". Conta uma estudante: "Certa vez, na escola, a professor reclamou com a minha mãe que eu não sabia pintar, que eu não combinava as cores. Eles tinham um livro de pintura, valia nota. Então eu tinha que pintar direito, dentro da linha, no limite e com as cores certas". (C. Q.).

Sobre a presença da arte na Escola, a partir do primeiro ciclo, é marcante o relato de produções para épocas festivas (fazer os fatos/fantasias de carnaval, por exemplo). Na escrita de uma estudante, sobre o espaço da arte na escola, há a indicação de "[...] experiências pobres, apenas se preocupavam em que não saíssemos dos riscos e em considerar os trabalhos bonitos ou feios" (C.).

A arte na Escola Básica aparece majoritariamente como fazer, efetivado com atividades que envolviam: pintura, como reprodução de obras de arte/quadros e pintura em vidro; produção de máscaras de gesso; desenhos; experimentação de diferentes técnicas; contato com diversos materiais; fazer gravuras e organização da exposição com as produções. Também contam sobre o conhecimento de alguns artistas e trabalhos a partir de suas obras. A criação e apresentação de peças teatrais é citada como oportunidade para a aprendizagem de todo o processo de apresentação de uma peça (dramatização em si, o cenário, adereços, narrador da história) e a produção de espetáculos musicais também aparece entre as experiências positivas rememoradas.

Nas palavras de uma participante, ao entrar no $2^{\circ}$ Ciclo da Educação Básica, por apresentar na estrutura curricular disciplinas específicas de arte, é que teve oportunidade de desenvolver sua sensibilidade artística. Ela diz: "Minha sensibilidade começou a ser formada, mais especificamente nas artes plásticas. Tive um conjunto de professores que nos disponibilizaram oportunidades de experimentar diferentes técnicas e conhecer alguns

\footnotetext{
${ }^{3}$ Deixamos assim para outro escrito a análise das experiências nos contextos familiares, comunitários ou dos media.
} 
artistas" (S.). Nesta época da escolaridade também são lembradas como significativas as atividades extracurriculares disponibilizadas, como o Clube das $\operatorname{Artes}^{4}$ ( $5^{\circ}$ ano) e Clube de teatro $\left(5^{\circ}\right.$ e $6^{\circ}$ ano).

De outra maneira, a escola revela-se como oportunidade para a ampliação de experiências, no contato com o patrimônio histórico e cultural. Todas as participantes citam visitas, passeios e saídas de estudo para sítios históricos, relacionados à ciência e à natureza, e espaços artístico-culturais. Citam as seguintes visitas: 1) $1^{\circ} \mathrm{Ciclo}\left[1^{\circ}\right.$ ao $4^{\circ}$ ano]: Pavilhão do Conhecimento; Jardim zoológico; Oceanário; Museu do Hospital e das Caldas; Museu José Malhoa; Museu de Cerâmica. 2) $2^{\circ} / 3^{\circ}$ Ciclos [5 $5^{\circ}$ ao $9^{\circ}$ ano]: Museu da presidência da república; Pavilhão do conhecimento; Museu de Beja; Santuário de Fátima; Casa Museu São Rafael; Centro Cultural de Belém; Padrão dos Descobrimentos; Praça de Touros de Caldas da Rainha. Nos anos do ensino secundário, apontam: Palácio de Cristal; Convento de Mafra; Museu de Salamanca; Santuário de Bordéus; Museu do Prado em Madrid; Casa do Fernando Pessoa, em Lisboa.

Sobre o espaço da arte na formação universitária, as narrativas trazem referências de saídas para visita a museus, para assistir a espetáculos de música e ir ao teatro. Foram apontadas explicitamente visitas à Fundação Eugenio de Almeida - Évora, ao Museu da Marioneta - Lisboa, e ao Museu da imagem em movimento - Leiria. Quanto às disciplinas curriculares, as narrativas indicam a presença de todas as expressões artísticas - artes visuais, música, expressão motora, expressão dramática -, as quais são trabalhadas, segundo contam as estudantes, com integração teórico-prática.

As diferentes áreas de expressão/educação artística estão presentes ao longo da formação, quer enquanto área de conhecimento próprio e autónomo ${ }^{5}$, quer numa perspectiva integrada $^{6}$ e articulada com as várias dimensões do conhecimento, quer ao nível de aprofundamento específico e didático/instrumental.

\section{CONSIDERAÇÕES FINAIS}

\section{Finalizar, afirmar: "[a Arte] é um conhecimento, necessário para o educador da infância"}

A formação estética dá-se em íntima relação com os processos de percepção, de imaginação, de interpretação, no mundo e com o mundo, por meio dos quais a sensibilidade é alargada. As vozes das estudantes/educadoras em formação reiteram a concepção da dimensão estética como aquilo que conecta (VECCHI, 2013), que atravessa a existência, que é tecida ao longo da vida com os fios da sensibilidade e da razão, da cognição e do afeto, definindo as possibilidades de construção de sentidos e/ou seu refinamento.

\footnotetext{
${ }^{4}$ No sistema Educativo português, sobretudo no $3^{\circ}$ Ciclo e Ensino Secundário, as escolas dispõem da possibilidade de proporcionar espaços curriculares de opção como sejam: Oficina de Teatro, de Dança ou Cinema, e potenciar a criação de Clubes de Artes, extracurriculares, de acordo com Projetos Educativos e recursos das Escolas.

${ }^{5} \mathrm{Na}$ LEB - Educação, Expressão e Jogo Dramático; Educação e Expressão Visual e Plástica, Educação, Expressão e Cultura Musical com 5 ECTS cada + 2 optativas de 2,5 ECTS de entre as seguintes: Temas Aprofundados de Educação e Exp. Dramática; Temas Aprofundados de Educação e Exp. Plastica, Temas Aprofundados de Educação e Exp. Musical. No Mestrado - duas optativas de entre as seguintes: Laboratório de Técnicas Projetivas de Expressão Dramática, Educação e Cultura Visual, Culturas Musicais

${ }^{6} \mathrm{Na}$ LEB - Oficina de Integração das Expressões; No Mestrado: Educação e Expressões Artísticas na infância, Projeto Integrado de Artes, Humanidades, Ciências e Tecnologias
} 
O estético, como dissera Galeffi (2007), reside naquilo que cada um é em sua existência, na relação com o mundo, e as experiências com a arte, a cultura e a natureza, tramadas na relação com outros significativos, podem afetar todos os sentidos, penetrando a pele, olhos, ouvidos, olfato, paladar, rompendo a indiferença, reafirmando a vida. É disso que se trata quando se coloca em foco a discussão sobre a formação estética docente.

Os encontros em forma de ateliês transformam-se em oportunidades para a abertura de canais expressivos, para (re)conexões outras, a medida em que, pelos fazeres artísticosartesanais propostos, suscitavam/alimentavam olhares multidirecionados, para dentro e para fora do sujeito aprendente. Por exemplo: se as narrativas demonstravam que as experiências com o desenho foram malsucedidas ao longo da vida escolar, o processo dos ateliês, com espaço para o exercício/brincadeira com o desenho, permitiu-lhes a descontração, a liberação, a diversão que, de certa forma, franqueavam possibilidades para o reencontro com fazeres artístico-expressivos.

Para professores em formação, que têm no horizonte a atuação junto de crianças que atravessam momentos de experimentações, conhecimento e apropriação de linguagens, entre o gráfico e o pictórico, reputamos ser da maior importância atentar para as formas como tais linguagens estão localizadas na história de vida dos estudantes-docentes em formação. De certo modo, revisar suas concepções sobre não saber desenhar pode ser determinante para a revisão crítica de práticas pedagógicas que ainda se utilizam de desenhos prontos para as crianças apenas pintarem. Essa mão que toma uma folha com reproduções de desenhos para as crianças colorirem é a mão de um professor que, no final, também foi expropriado. A perda progressiva do desenho da criança, como anotara ALBANO (2002), faz-se por meio de práticas pedagógicas escolares, protagonizadas, por vezes, por professores que foram roubados em suas oportunidades de criar, imaginar e traçar; que também perderam seus desenhos. Tomar consciência do seu próprio desenho perdido pode ser um passo decisivo para aprender a olhar o desenho da criança, respeitá-lo e contribuir para a ampliação de suas possibilidades gráfico-pictóricas.

Em outra direção, notaremos que essa mesma escola que deixa pouco espaço para a criação, revela-se como canal potente de ampliação de experiências além muros escolares, oferecendo oportunidades para o contato com o patrimônio histórico e cultural. Saídas para passeios e visitas de estudo para sítios históricos, relacionados à ciência e à natureza, e espaços artístico-culturais, são também nomeadas entre as experiências no início da escolaridade das estudantes portuguesas.

Por meio da rememoração e da escrita de si, no exercício autobiográfico, os professores/educadores em formação podem (re)encontrar elementos constituintes de suas sensibilidades, localizar e articular fatos, acontecimentos, relações, experiências - para compreendê-las, reafirmá-las ou superá-las. O ateliê biográfico de projeto, gestando interpelações narrativas que denunciam perdas e deixam entrever desejos, pode também contribuir com esses processos de ressignificação (OSTETTO, 2019).

Não há dúvida do reconhecimento da formação artístico-cultural no curso de formação como uma necessidade demandada pela prática profissional que desenvolverão. Sendo a arte um campo de conhecimento presente no currículo escolar, é preciso ter esse conhecimento para trabalhar com educação, com crianças, como bem sintetizou uma das participantes da pesquisa: "É preciso fazer para gostar de arte; fazendo pode-se desmistificar a ideia de que não se tem jeito, ou de que não se gosta disso e daquilo. Por exemplo, a dramatização: alguém pode não ter jeito, mas vai achando. Porque [a arte] é um conhecimento, necessário para o educador da infância." (M.). 
Prestar atenção aos itinerários de formação sensível dos estudantes participantes da nossa pesquisa, permitiu-nos suspeitar/identificar elementos-chave dos processos de educação estética ao longo da vida e, com eles, refletir e reafirmar que os cursos de formação docente devem garantir espaço-tempo para experimentação, expressão, criação, liberdade de movimento. Para além de aulas de arte isoladas, destaca-se a importância de cultivar articuladamente sensibilidade e pensamento no contato com a natureza, a cultura, a arte e a comunidade, ao mesmo tempo que se possibilita a reativação de experiências biográficas que permitam desocultar a formação da sensibilidade estética enquanto percurso de continuidade /descontinuidade ao longo da vida.

A análise também nos conduz a validar a ideia do isomorfismo pedagógico (FOLQUE; LEAL-DA-COSTA; ARTUR, 2016) como estratégia de formação. Segundo Sérgio Niza (2009), o isomorfismo pedagógico refere-se à

\begin{abstract}
[...] estratégia metodológica que consiste em fazer experienciar, através de todo o processo de formação, o envolvimento e as atitudes; os métodos e os procedimentos; os recursos técnicos e os modos de organização que se pretende que venham a ser desempenhados nas práticas profissionais efetivas dos professores. (NIZA, 2009, p. $352)$.
\end{abstract}

No contexto que vimos analisando, referente à formação estética docente, significa que, do mesmo modo como potenciamos as sensibilidades, os saberes e as experiências das crianças no seu processo educativo como fator determinante para uma educação onde as mesmas assumam protagonismo, as propostas em que as estudantes-professoras-educadoras em formação tenham as suas experiências, saberes e sensibilidades validados/legitimados precisam ser potenciadas. No atravessamento das múltiplas dimensões envolvidas no percurso de formação docente, reconhecer tais fatores é fundamental, também, para sustentar relações de aprendizagem que visem a participação e, a partir dela, a ampliação de repertórios, no contexto da cultura e da cooperação.

De tal forma, se a formação estética vai, necessariamente, além das propostas da escola e/ou curso de formação, assim como acontece com a educação das crianças, é imprescindível tomar as experiências e saberes sensíveis como ponto que é ao mesmo tempo apoio e alavanca para a continuidade de processos criativos e criadores, ampliando-os.

\title{
REFERÊNCIAS
}

ALBANO, A. A. O espaço do desenho: a educação do educador. 9. ed. São Paulo: Loyola, 2002.

BEZELGA, I. Brincar, fruir, experimentar! A presença das artes na formação em educação da Universidade de Évora. Poiésis, Unisul, Tubarão, v.12, n.21, p.167-184, jan,/jun. 2018.

DELORY-MOMBERGER, C. Formação e socialização: os ateliês biográficos de projeto. Educação e Pesquisa, São Paulo, v.32, n.2, p.359-371, maio/ago.2006.

DUARTE Jr., J. F. O sentido dos sentidos: a educação (do) sensível. Curitiba: Criar, 2001.

FOLQUE, M. A. A formação de educadores de infância: da exigência e complexidade da profissão ao projeto de formação na UniverCidade de Évora. Poiésis, Unisul, Tubarão, v.12, n. 21, p. 32-56, jan,/jun. 2018.

FOLQUE, M. A.; LEAL DA COSTA, C.; ARTUR, A. A formação inicial e o desenvolvimento profissional de educadores/professores monodocentes: os desafios do isomorfismo pedagógico. In: CORRÊA, C. H. A.; CALVANCANTI, L. I. P.; BISSOLI, M. F. Formação de professores em perspectiva. Manaus: EDUA, 2016. p. 177-235. 
FOX, M. Guilherme Augusto Araújo Fernandes. São Paulo: Brinque Book, 1995.

FREIRE, P. Pedagogia da autonomia. Saberes necessários à prática educativa. 30. ed. São Paulo: Paz e Terra, 2004.

GALEFFI, D. A. Educação estética como atitude sensível transdisciplinar: o aprender a ser o que se é propriamente Em Aberto, Brasília, v. 21, n. 77, p. 97-111, jun. 2007.

HILLMAN, J. Cidade e alma. São Paulo: Studio Nobel, 1993.

HERMANN, N. Ética e estética: a relação quase esquecida. Porto Alegre: EDIPUCRS, 2005.

HERMANN, N. A abertura ao outro. In: HERMANN, Nadja. (Org.). Ética e Educação: outra sensibilidade. Belo Horizonte: Autêntica, 2014. p. 121-151.

LEITE, M. I.; OSTETTO, L. E. In: OSTETTO, L. E.; LEITE, M. I. Arte, infância e formação de professores. Campinas, SP: Papirus, 2004.

NIZA, S. Contextos cooperativos e aprendizagem profissional: a formação no Movimento da Escola Moderna. In: FORMOSINHO, João (Org.). Formação de professores: aprendizagem profissional e ação docente. Porto: Porto Editora, 2009. p. 345-362.

NÓVOA, A. Os professores e as histórias da sua vida. In: NÓVOA, A. (Org.). Vidas de professores. Porto: Porto Editora, 2007. 2. ed. p.11-30.

NUSSBAUM, M. Sem fins lucrativos: por que a democracia precisa das humanidades. São Paulo: Martins Fontes, 2015.

OSTETTO, L. E. Observação, registro, documentação: nomear e significar experiências. In: OSTETTO, L. E. (Org.). Educação infantil: saberes e fazeres da formação de professores. Campinas: Papirus, 2008. p.13-32.

OSTETTO, L. E. Ser professor de educação infantil entre buscas além dos hábitos de pensar e fazer. In: PINHO, S. Z. de (Org.). Formação de educadores: dilemas contemporâneos. São Paulo: Editora Unesp, 2011. p. 155-167.

OSTETTO, L. E. Fazer à mão para falar de si: a dimensão estética na formação e nas narrativas de professores. In: MONTEIRO, F. de A.; NACARATO, A. M.; FONTOURA, H. A. da. (Orgs.) Narrativas docentes, memórias e formação. Curitiba-PR : CRV, 2016, v.1. p. 143-159.

OSTETTO, L. E.; BERNARDES, R. K. Modos de falar de si: a dimensão estética nas narrativas autobiográficas. Pró-Posições (UNICAMP. Impresso), v.26, p.161 - 178, 2015.

OSTETTO, L. E.; SILVA, G.D. de B. Formação docente, Educação Infantil e arte: entre faltas, necessidades e desejos. Revista Educação e Cultura Contemporânea, 15 (41), p. 260 287, 2018.

PERISSÉ, G. Estética e educação. Belo Horizonte: Autêntica, 2009.

QUEIRÓS, B. C. de. Os cinco sentidos. São Paulo: Global, 2009.

RINALDI, C. Diálogos com Reggio Emilia; escutar, investigar e aprender. São Paulo: Paz e Terra, 2012.

SILVEIRA, P. A página violada: da ternura à injúria na construção do livro de artista. Porto Alegre: UFRGS, 2001.

VECCHI, V. Arte y creatividad en Reggio Emilia; el papel de los talleres y sus possibilidades en educación infantil. Madrid: Ediciones Morata, 2013. 
WARSCHAUER, C. A roda e o registro: uma parceria entre professor, alunos e conhecimento. Rio de Janeiro: Paz e Terra,1993.

Recebido em: 16/05/2019

Aprovado em: 19/07/2019 